\title{
RISCO DO USO DO ELETROCAUTÉRIO EM PACIENTES PORTADORES DE ADORNOS METÁLICOS
}

\author{
Risk of the use of electrocautery in patient with metallic ornaments \\ Cristina Toledo AFONSO, Alcino Lázaro da SILVA, Dreyfus Silva FABRINI, \\ Carla Toledo AFONSO, Marcelo Giusti Werneck CôRTES, Ludmila Leite SANT'ANNA
}

Trabalho realizado no Departamento de Cirurgia da Universidade Federal de Minas Gerais, Belo Horizonte, MG, Brasil

DESCRITORES - Eletrocirurgia. Eletrocoagulação. Ética médica.

\section{Correspondência:}

Alcino Lázaro da Silva,

e-mail: franciscoalberto@superig.com.br

Fonte de financiamento: não há

Conflito de interesses: não há

Recebido para publicação: 28/06/2010

Aceito para publicação: 23/07/2010

HEADINGS - $\quad$ Electrosurgery.

Electrocoagulation. Ethics, medical.
RESUMO - Introdução - A eletrocirurgia é tecnologia conhecida há longo tempo que, atualmente, tem adquirido cada vez mais destaque. Apesar disso, ainda apresenta vários riscos quanto à sua utilização. Várias lesões podem ser causadas por eletrocautérios, sendo as queimaduras a complicação mais frequente. Nem sempre existe a cooperção do paciente frente a medidas preventivas. Método - Revisão da literatura pertinente em função de questionamento jurídico de paciente que se negou a retirar seus ornamentos no início de procedimento cirúrgico, já estando ela na sala de operações. Conclusão - É essencial o conhecimento dos fundamentos da eletrocirurgia, seu uso correto, equipamento seguro, monitoramento constante e investigação imediata diante de quaisquer suspeitas, para minimizar o risco de acidentes em paciente com adornos metálicos, e a cooperação do paciente na obediência das medidas preventivas de acidentes deve ser obrigatória.

ABSTRACT - Introduction - Electrosurgery technology is known in a long time ago, and has gained increasing prominence. Nevertheless, it still presents many risks as to its use. Several lesions can be caused by electrocautery, and burns are the most frequent complications. There is not always patient's cooperation regarding preventive measures. Method - Review of relevant literature on the basis of legal questioning of a patient who refused to remove their ornaments at the beginning of surgery, being already in the operating room. Conclusion - It is essential to have the knowledge of the fundamentals of electrosurgery, its correct use, safety equipment, constant monitoring and immediate investigation to minimize the risk of accidents in patients with metal ornaments, and patient cooperation in obeying the preventive measures of accidents should be mandatory.

\section{INTRODUÇÃO}

$\mathrm{O}$ uso terapêutico da cauterização já é conhecido há longo tempo e remonta à época de Hipócrates. Atualmente, a eletrocirurgia tem adquirido cada vez mais destaque e vem se tornando tecnologia amplamente utilizada nas salas de cirurgia. Apesar disso, ela ainda apresenta vários riscos para o paciente, o cirurgião e toda a sua equipe.

As principais complicações relacionadas ao uso de eletrocautérios são queimaduras, explosões de misturas combustíveis, incluindo gases anestésicos e intestinais, estimulação de tecidos excitáveis e interferência com instrumentos e marca-passos. A queimadura, entretanto, é a complicação mais frequente ${ }^{8,13}$.

$\mathrm{O}$ cirurgião e sua equipe não precisam conhecer todos os pormenores da eletrocirurgia, mas devem entender o seu funcionamento e alguns de seus princípios, bem como conhecer medidas preventivas e ações corretivas que devem ser empregadas na minimização do risco de lesões desnecessárias.

MÉTODO

Revisão da literatura referente aos principais métodos utilizados em centros cirúrgicos foi motivada por um caso de mulher de 55 anos, em pré- 
operatório para colecistectomia videolaparoscópica. Ela teve sua operação suspensa, minutos antes de ser iniciada, em razão da recusa de retirar os anéis metálicos de seus dedos devido à incapacidade de o fazer sem danificá-los. Com base no ocorrido, a paciente moveu consulta ao Conselho Regional de Medicina de Minas Gerais, questionando a real necessidade de se retirar adornos metálicos para realização de operações que utilizam o eletrocautério.

O questionamento da paciente e a escassez de produção científica relacionada ao uso da eletrocirurgia motivou a elaboração deste trabalho, que visa a discutir os aspectos relacionados às complicações e ao emprego adequado dessa tecnologia.

\section{RESULTADOS}

O princípio da eletrocirurgia baseia-se na passagem de uma corrente elétrica de alta frequência pelos tecidosalvo. A corrente elétrica, que é produzida por um gerador e liberada através de um eletrodo ativo, percorre o corpo do paciente e sai através de um eletrodo neutro ou dispersivo (placa de dispersão). Ao encontrar a resistência do tecido humano, essa corrente elétrica é transformada em calor. Vários efeitos terapêuticos, seja de corte ou de coagulação, podem ser alcançados, dependendo da aplicação do calor. Tais efeitos dependem da resistência dos tecidos, do tempo da exposição, da superfície exposta e da densidade da corrente elétrica ${ }^{14}$.

A densidade da corrente, definida como a quantidade de eletricidade que flui através de uma área do tecido, é o mais importante conceito na compreensão da eletrocirurgia, uma vez que o tecido exposto à maior densidade de corrente sofrerá maiores efeitos. Aspecto importante da densidade se reflete na escolha do local em que é colocada a placa de dispersão. Por exemplo, se ela é colocada próximo ao campo operatório, menor quantidade de energia é perdida no circuito e, assim, densidades de corrente menores são necessárias para se alcançarem os efeitos desejados no tecido. Por outro lado, se a placa for colocada mais distante, maior quantidade de energia será perdida, devido à resistência do corpo, o que exige maiores densidades e acarreta maiores riscos de lesões ao paciente ${ }^{14}$.

Outro fator importante é a resistência dos tecidos, pois quanto maior a resistência à corrente elétrica, maior a quantidade de calor produzido. Os corpos que oferecem menor resistência são os condutores, tais como os metais, o solo, as soluções iônicas e o corpo humano. Os tecidos adiposo e ósseo apresentam resistência superior à da pele, à do tecido muscular e à das áreas bem vascularizadas. Isso é importante na escolha do local em que se posiciona a placa dispersiva, pois se deve dar preferência a áreas de tecido altamente vascularizadas e de maior musculatura, evitando-se áreas de maior concentração de gordura e proeminências ósseas. A resistência é também importante para se entender a obrigatoriedade de se retirarem todos os materiais condutores, ou seja, de baixa resistência, como, por exemplo, jóias, brincos, "piercings", colchetes, botões e outros adornos metálicos, que podem oferecer um caminho alternativo para a saída da corrente elétrica do corpo do paciente, o que pode produzir queimaduras, assim como perda da eficácia do processo eletrocirúrgico. Vários trabalhos na literatura relatam a ocorrência de queimaduras nos locais com adornos metálicos, com eletrodos de eletrocardiograma e de eletroencefalograma, com sondas de temperatura retal ou da pele, e com equipamentos de monitoramento interno que utilizam agulha ${ }^{6,14}$.

A duração da corrente, ou seja, o tempo de exposição a ela é um fator que também influencia nos efeitos da sua passagem pelo corpo humano, pois quanto maior o tempo de exposição, maiores os efeitos e os riscos de lesões ${ }^{14}$.

A área exposta à corrente elétrica também interfere nos efeitos sobre os tecidos, pois, para uma mesma quantidade de energia, uma menor área de superfície deverá conduzir a corrente com maior densidade, o que leva a maiores efeitos deletérios. Esse princípio é aplicado na utilização da placa dispersiva. Ela deve ter tamanho suficiente para manter ampla área de dispersão da eletricidade, de forma a não causar danos aos tecidos. Além disso, devem ser usadas geléias e pastas, que aumentam o contato com a pele e reduzem a resistência oferecida por ela. Se a placa não estiver completamente aderida ou não for suficiente o fluido de irrigação entre a placa e a pele, a superfície total de dispersão se torna menor, o que oferece maiores riscos ${ }^{12}$.

Existem duas modalidades de eletrocirurgia: 0 sistema monopolar e o bipolar. Na técnica monopolar, são utilizados um eletrodo ativo, para conduzir a corrente, e um eletrodo de dispersão, para a saída da corrente. $\mathrm{Na}$ técnica bipolar, são utilizados dois eletrodos idênticos (geralmente semelhantes a uma pinça ou a uma tesoura), que formam um só instrumento bipolar. No sistema monopolar, o eletrodo neutro está distante do eletrodo ativo, enquanto no sistema bipolar, esses eletrodos estão separados por pequena distância ( $1 \mathrm{~mm}$ a $3 \mathrm{~mm}$ ), limitando-se o fluxo da corrente elétrica no tecido.

No sistema monopolar, a corrente elétrica, ao ser transmitida pelo eletrodo ativo, percorre maior área do corpo do paciente antes de encontrar o eletrodo dispersivo. Dessa forma, esse sistema oferece maiores riscos, pois maior quantidade de tecido está exposta à eletricidade. As lesões em eletrocirurgia monopolar ocorrem mais frequentemente no local da placa dispersiva, mas também em locais com eletrodos de monitoração e em sítios de contato acidental com objetos de metal, que funcionam como caminho alternativo para a dispersão da eletricidade. No sistema bipolar, o fluxo da corrente elétrica limita-se ao espaço entre os dois eletrodos, a corrente elétrica não atravessa o corpo do paciente, o que virtualmente elimina tais mecanismos de lesões. A energia elétrica proporcionada pelo eletrodo 
bipolar, por ser menor, produz, comprovadamente, lesões térmicas mais superficiais e mais localizadas que as produzidas pelo eletrodo monopolar. Vários estudos demonstram que o índice de complicações com o eletrodo bipolar é significativamente menor ${ }^{1}$.

As queimaduras - principal complicação relacionada ao uso da eletrocirurgia -, são basicamente secundárias a três causas. A primeira é o trauma térmico não intencional ou por uso inapropriado do eletrodo ativo. A segunda é a ocorrência de um trauma térmico indesejável na região da placa, também chamado de dano tecidual de retorno. Quando não ocorre bom contato entre a placa e a pele, a energia é dispersa em menor área, o que aumenta o aquecimento no local e causa dano. Uma terceira causa de queimaduras pode ocorrer quando a corrente elétrica assume um caminho indesejável através do corpo do paciente que não o eletrodo de dispersão (placa). Materiais e adornos metálicos podem funcionar como um "fio-terra", ou seja, são criadas vias alternativas para a passagem da corrente elétrica, e aumenta o risco de lesão nesses locais' ${ }^{2,3}$.

Visando a reduzir os riscos relacionados à aplicação da eletrocirurgia, foram estabelecidas algumas recomendações quanto ao uso dessa tecnologia, que servem como guia de medidas preventivas para todos os profissionais que atuam no centro cirúrgico.

Ponto fundamental na prevenção de acidentes com o uso da eletrocirurgia é o posicionamento correto do paciente na mesa cirúrgica. O contato com objetos metálicos do paciente ou da mesa e com eletrodos de monitoramento pode concentrar a corrente, ou acarretar sua fuga, e provocar lesões. Os adornos metálicos devem ser obrigatoriamente retirados, e os eletrodos colocados o mais distante possível do campo cirúrgico. Devem-se utilizar dispositivos isolantes na mesa e nos apoios de braços e pernas, para evitar fuga da corrente através de áreas metálicas, e compressas secas entre braços, tronco ou pernas, para evitar concentração de corrente nas áreas com acúmulo de fluidos ${ }^{4,5,7}$.

Deve ser confirmada a potência do eletrocautério antes da ativação, que deve ser a mais baixa potência efetiva possível, a fim de que se atinja o efeito desejado para corte e coagulação. Se o cirurgião solicitar contínuo aumento de potência ou se ocorrer resposta não usual do paciente ou, ainda, nterferência no sinal de monitoramento durante o uso do eletrocautério, faz-se necessário investigar todo o circuito à procura de falha ${ }^{10}$.

Os sistemas de alarme devem funcionar todo o tempo. O volume do indicador sonoro de atuação do aparelho deve ser mantido em nível audível, para que seja alertado imediatamente quando o eletrocautério for acionado inadvertidamente ou quando esse não estiver funcionando adequadamente ${ }^{6}$.

O local da placa dispersiva é geralmente ditado pelo sítio cirúrgico, sendo ela posicionada o mais próximo possível do campo, preferencialmente em pele limpa e seca, em área bem vascularizada e com maior massa muscular, para melhor condutibilidade da eletricidade. Por outro lado, devem ser evitadas áreas com grande quantidade de pelos, de cicatrizes e saliências ósseas, uma vez que diminuem o contato com a placa e conduzem de forma pior a eletricidade. Deve-se evitar também a colocação do eletrodo dispersivo sobre tatuagens, muitas das quais contêm corantes metálicos. O eletrodo ativo deve ser colocado longe do campo quando não está em uso, evitando-se sua ativação não intencional e lesões ${ }^{10,11}$.

Os eletrodos ativos não devem ser usados na presença de gases anestésicos e de agentes inflamáveis, como anti-sépticos para a degermação da pele. Isso é particularmente importante em operações otorrinolaringológicas e nas da cabeça e pescoço, devido à proximidade com os gases anestésicos ${ }^{4}$.

Os pacientes usuários de marca-passo devem ser continuamente monitorados, pois, embora os modernos sejam desenhados de modo que fiquem protegidos à passagem de corrente, ainda estão sujeitos a interferência da eletrocirurgia, podendo ser danificados irreparavelmente ou terem sua função alterada. Precauções adicionais devem ser tomadas para que se minimizem acidentes. São elas: checar com o cardiologista as funções do marca-passo durante o uso da eletrocirurgia; ter uma unidade de programação de marca-passo à mão para ajustá-lo no modo assincrônico; ter um desfibrilador à mão para uso imediato no caso de emergências; manter todos os cabos e fios da unidade eletrocirúrgica distantes do marca-passo e de suas conexões; usar o ajuste de potência no gerador o mais baixo possível; usar eletrocirurgia bipolar sempre que possível, mas, caso necessário, utilizar a eletrocirurgia monopolar e assegurar-se de que a distância entre os eletrodos ativo e dispersivo seja a mais curta possível ${ }^{12}$.

Além dos aspectos técnicos discutidos acima, o caso que motivou esta revisão levanta também algumas questões bioéticas em relação ao emprego da eletrocirurgia.

A bioética surgiu para pensar a respeito das relações humanas - e com respeito a elas - frente aos novos valores ou problemas sociais. Como consequência, grandes mudanças foram introduzidas pelo mundo moderno nas relações sociais, incluindose, entre elas, a relação entre médico e paciente, que antes primava pela verticalidade imperativa do médico, e que paulatinamente se transmuda em horizontalidade democrática na tomada de decisões.

Essas mudanças, além de serem resposta aos anseios da comunidade científica, tornam-se um passo constante para o balizamento dos avanços científicos e tecnológicos, e dão sentido maior de dignidade à profissão médica, estabelecendo novas normas éticas de conduta, que devem nortear a vida do médico, tanto no exercício profissional, como fora dele.

Tal balizamento deve ser realizado por meio de cinco referenciais ou princípios básicos: autonomia, 
não-maleficência, beneficência, justiça e alteridade.

A autonomia decorre do direito de liberdade (poder de governar a si próprio) e da ação (capacidade de ação intencional).

O princípio da não-maleficência, que propõe a obrigação de não infligir dano intencional e prescreve que o médico não realize condutas que prejudiquem o paciente, deriva da máxima da ética médica "primum non nocere".

O princípio da beneficência decorre do termo "bonum facere" e significa que se deve fazer o bem para o paciente, ou seja, fazer o maior bem, com o menor dano possível.

O da justiça defende o direito e o privilégio iguais para todos os seres humanos.

A alteridade também está incluída entre os princípios, pois o sujeito da ação médica é o outro, ou seja, um ser humano distinto. Isso gera a ontoética, a ética do ser humano.

Baseando-se nos princípios acima descritos, o médico tem o compromisso ético de oferecer, na medida do possível, todos os cuidados necessários ao paciente, amparando-o na sua doença, realizando, com o melhor de sua habilidade e julgamento, os procedimentos necessários para promover benefício, melhora ou bem-estar do paciente, bem como protegendo-o contra acidentes, danos ou lesões adicionais desnecessárias. Uma vez que o médico tem o conhecimento, sua não-aplicação passa a ser infortúnio por sua parte. Por outro lado, cabe ao paciente cooperar para que todos os passos de segurança sejam aceitos e seguidos 9 .

O per-operatório oferece riscos para o paciente, do momento da sua entrada no bloco cirúrgico até o retorno à unidade de origem, e a eletrocirurgia constitui um desses riscos. Todos os membros da equipe estão envolvidos na prevenção deles, mas a responsabilidade maior de verificar a adequação do processo é do cirurgião.

\section{CONCLUSÃO}

É essencial o conhecimento dos fundamentos da eletrocirurgia, seu uso correto, equipamento seguro, monitoramento constante e investigação imediata diante de quaisquer suspeitas, para minimizar o risco de acidentes em paciente com adornos metálicos, e a cooperação do paciente na obediência das medidas preventivas de acidentes deve ser obrigatória.

\section{REFERÊNCIAS}

1. Aigner N, Fialka C, Fritz A, Wruhs O, Zoch G. Complications in the use of diathermy. Burns. 1997;23(3)256-264.

2. Cunnington J. Facilitating benefit minimizing risk: responsibilities of the surgical practitioner during electrosurgery. J. Perioper. Pract. 2006; 16(4)195-202.

3. Fong EP, Tan WTL, Chye LT. Diathermy and alcohol skin preparations - a potential disastrous mix (case report). BURNS. 2000;26(7)673-675.

4. Geddes LA, Tacker WA, Cabler P. A new electrical hazard associated with the electrocautery. Med Instrum. 1975;9(2):112-3.

5. Guiloff AK, Cabbabe EB. A simple method to protect tissue from accidental cautery burns. Ann Plast Surg. 1986;17(2):169.

6. Hutchinsson B, Baird MG, Wagner S. Electrosurgical safety. AORN J. 1998;68(5)830-844.

7. Isager $P$, Lind $T$. Accidental third-degree burn caused by bipolar electrocoagulation. Injury. 1995;26(5):357.

8. Lee TW, Chen TM, Chen TY, Chen SG, Chen SL, Chou TD, Chou $\mathrm{GH}$, Lee $\mathrm{CH}$, Wang HJ. Skin injury in the operating room. Injury. 1998;29(5):345-347.

9. Maciel RARS. Sindicância $n^{\circ} 5867 / 2007$ do Conselho Regional de Medicina de Minas Gerais.

10. Nduka CC, Super PA, Monson JR, Darzi AW. Cause and prevention of electrosurgical injuries in laparoscopy. J. Am. Coll. Surg. 1994;179:161-170.

11.Paugh $\mathrm{DH}$, White $\mathrm{KW}$. Fire in the operating room during tracheotomy: a case report. AANA J. 2005;73(2)97-100.

12. Trindade MRM, Grazziotin RU, Grazziotin RU. Eletrocirurgia: sistemas mono e bipolar em cirurgia videolapaposcópica. Acta Cir. Bras. 1998;13(3)1-17.

13. Vedovato JW, Polvora VP, Leonardi DF. Burns as a complication of the use of diathermy. Journal of Burn Care \& Rehabilitation. 2004;25(1):120-123.

14. Waldron RP, Copeland GP, Murphy AF. Surgical diathermy: a potential hazard. Br J Clin Pract. 1984;38(7-8):283. 